\title{
Maritime zones delimitation - Problems and solutions
}

\author{
Christos Kastrisios, ${ }^{\mathrm{a}}$ Lysandros Tsoulos ${ }^{\mathrm{a}}$ \\ ${ }^{a}$ National Technical University of Athens, Cartography Laboratory, Zographou, Attica, Greece; christoskas@hotmail.com, \\ lysandro@central.ntua.gr
}

\begin{abstract}
The delimitation of maritime zones and boundaries foreseen by the United Nations Convention on the Law of the Sea (UNCLOS) is a factor of economic growth, effective management of the coastal and ocean environment and the cornerstone for maritime spatial planning. Maritime zones and boundaries form the outermost limits of coastal states and their accurate delineation and cartographic portrayal is a matter of national priority. Although UNCLOS is a legal document, its implementation -at first place- is purely technical and requires -amongst others- theoretical and applied background on Geodesy, Cartography and Geographic Information Systems (GIS) for those involved. This paper provides a brief historical background of the evolution of the UNCLOS, presents the various concepts of the Convention and identifies the problems inherent in the maritime delimitation process. Furthermore, it presents solutions that will facilitate the cartographer's work in order to achieve unquestionable results. Through the paper it becomes evident that the role of the cartographer and the GIS expert is critical for the successful implementation of maritime delimitation.
\end{abstract}

Keywords: Maritime zones, Boundaries delimitation, Territorial sea, Contiguous zone, Exclusive Economic Zone, Continental shelf

\section{Introduction}

After ten sessions of the 3rd United Nations Conference on the Law of the Sea, the Law of the Sea Convention (UN 1982) was opened for signature in Montego Bay, Jamaica, on 10 December 1982 and came into force on 16 November 1994, twelve months after receiving its sixtieth ratification. The 1982 Convention revised the previous 1958 Geneva Conventions codifying customary law and state practices of the time and introduced new provisions regarding maritime space. The UNCLOS represents the perpetual effort of coastal states to codify rights and duties over waters both adjacent to and distant from their territory and is the result of a long time process beginning in antiquity. Around the end of the 18th century, and after the so called "war of books" between the supporters of the Mare Liberum and Mare Clausum doctrines, it was internationally accepted that the sea is common to all humanity and no state is entitled to claim dominion over it, with the exception of a narrow zone of sea along states' coasts, mainly for protection purposes against piracy and other hostile actions. The exercise of effective control over that sea zone (the predecessor of the territorial sea zone) was limited by the range of cannons on the coasts (cannon shot rule), which at the time was recognized to be 3 nautical miles (NM) and hence the breadth of the zone that could be claimed by coastal states. Later, in the early 20th century, many nations demanded wider limits for the territorial sea and also jurisdiction over extended areas for protecting fish stocks; an area known as fishery zone. The first attempt of the international community to codify maritime zones and delimitation methods in 20th century failed (Hague Conference, 1930). On the contrary, the next attempt with the 1st UN Conference in Geneva (1958) came off and resulted in four separate treaties, i.e. the conventions on the Territorial Sea and Contiguous Zone, on the Continental Shelf, on the High Seas and that on Fishing and conservation of living resources of the High Seas. At the 2nd UN Conference, held in Geneva (1960), states tried to resolve the issues of the territorial sea and the fishery zone, with respect the maximum breadth of the zones, but that effort was unsuccessful and they did not come to an agreement. In contrast, after ten sessions (1973 - 1982), the 3rd Conference resulted in the public international law of the sea as it exists nowadays.

\section{Maritime limits and boundaries}

\subsection{Limits and rights}

The Convention parcels the sea into a variety of maritime zones a coastal state may claim (see Fig. 1). Each zone grants certain rights to the coastal state and carries certain obligations to the foreign states and vessels. Subject to UNCLOS, every state and vessel enjoy six freedoms in high seas, namely the freedom of navigation, the freedom of over flight, that of laying submarine cables and pipelines, the freedom of marine scientific research, of constructing artificial islands and installations and that of fishing. The general principle is the closer to the coast the greater the degree of rights for the coastal state, which consequently curtails some or all of the six freedoms for the foreign states and vessels (Kastrisios 2014). In detail the maritime zones foreseen by the Convention are:

- Internal Waters, which cover all water on the landward side of the baseline. The internal waters are considered part of the state's territory, and in that sense not a maritime zone. The coastal state exercises full sovereignty in internal waters, sovereignty which is applied over 
seabed, water column and air space, and postulates that foreign vessels and states are deprived of all of the high seas freedoms.

- Territorial Sea, measured from the baseline seaward, the breadth of which may not exceed 12 NM. The coastal state's sovereignty is extended beyond its land territory and internal waters in the territorial sea, but within this zone the freedom of innocent passage for the foreign vessels is retained.

- Contiguous Zone which is adjacent to the territorial sea and may not extend beyond $24 \mathrm{NM}$ from the baseline. Typically, that is $12 \mathrm{NM}$ wide, but may be more if a state claims territorial sea less than $12 \mathrm{NM}$. In the contiguous zone the coastal state has the jurisdiction to regulate and put laws into in order to prevent and punish infringements of its customs, fiscal, immigration or sanitary laws committed within its territory or territorial sea. Within contiguous zone the coastal state has no further rights and the high seas freedoms remain unaffected.

- Exclusive Economic Zone (EEZ), which is adjacent to the territorial sea and may not extend beyond $200 \mathrm{NM}$ from the baseline. In EEZ the coastal state has sovereign rights for the purpose of exploring and exploiting, conserving and managing the natural resources, both living or non-living and the jurisdiction to establish artificial islands or installations and to conduct scientific research. Coastal state is responsible for the protection of marine environment. Foreign vessels enjoy three of the six high seas freedoms, namely the freedoms of navigation, the freedom of over flight and that of laying submarine cables and pipelines.

- Continental Shelf which is again adjacent to the territorial sea but, in contrast to the other maritime zones, not only distance dependent. The outer limit of the continental shelf is constructed by the outer edge of the continental margin, or to a distance of $200 \mathrm{NM}$ from the baselines where the outer edge of the continental margin does not extend up to that distance, and the combined constraint line. More precisely, the outer limit is delineated as the combination of the following lines (see Fig.2):

1) The Gardiner Line, which is defined as the line where the thickness of sedimentary rocks is at least $1 \%$ of the distance to the foot of the continental slope,

1)The Hedberg line, which is the line $60 \mathrm{NM}$ from the foot of the continental slope,

2)The depth constraint line, which is $100 \mathrm{NM}$ from the $2500 \mathrm{~m}$ isobaths, and

3)The distance constraint line, which is a line $350 \mathrm{NM}$ from the territorial sea baselines.
4)The regime of continental shelf is similar to that of the EEZ but the rights it grants are limited to the seabed and subsoil, excluding the superjacent water column and airspace. Unlike EEZ, which has to be proclaimed, the sovereign rights of the coastal state over the continental shelf exist ipso facto and ab initio. In other words coastal state's rights over continental shelf "do not depend on occupation, effective or notional, or on any ex-press proclamation and, therefore, can be exercised at any time".

- High Seas are all parts of the sea that are not included in any of the above maritime zones. Over High Seas, all freedoms are retained for every state and the vessels flying their flag. Mention should be made to "The Area", which comprises the sea-bed, ocean floor and subsoil below the high seas with the exception of that which is claimed as a state's extended continental shelf (the part of the continental shelf extending beyond $200 \mathrm{NM}$ ). The Area with its resources is common heritage of mankind and must be used for the benefit of all states.

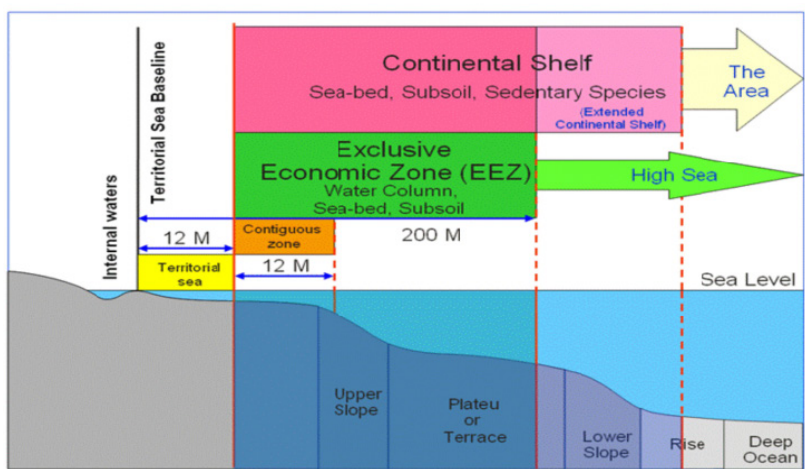

Fig. 1. Maritime zones of a coastal state. (Source: TALOS 2014)

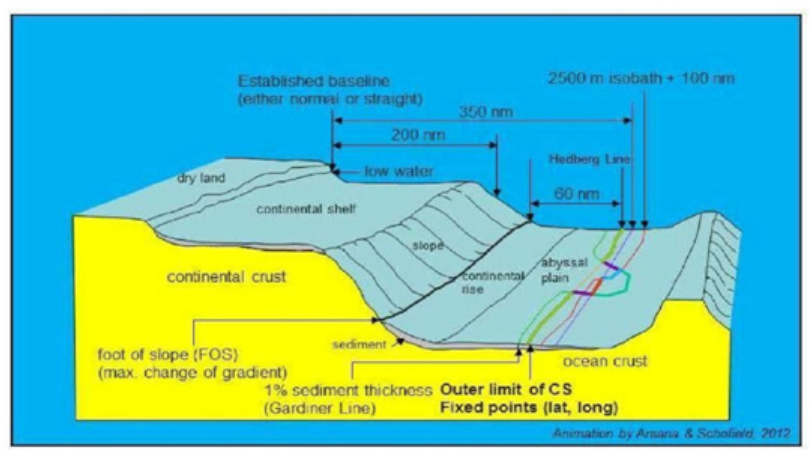

Fig. 2. Delineation of the outer limits of the continental shelf. (Source: TALOS 2014)

\subsection{General technical issues}

The UNCLOS provides the framework for the delimitation and delineation of maritime limits and the jurisdiction over maritime space. Yet it remains silent with respect to the technical aspects of the delimitation in a number of its provisions. This gap has been, to some 
extent, fulfilled by supporting documents, i.e TALOS (1982), states' practices and jurisprudence. In parallel cartographers developed methods for the implementation of the technical aspects. Formerly, the delimitation of maritime space was carried out solely with traditional graphical methods employed directly on charts of suitable scales. With the advent of computers, specialized software applications provided the technical expert with the ability to tackle problems that were difficult to handle. Tasks, such as geodetic computations on a surface of varying curvature like the ellipsoidal model of the earth's surface, have been resolved efficiently. Nevertheless, the methods themselves have not changed; on the contrary Geographic Information Systems (GIS) applications incorporated such methods.

According to UNCLOS provisions, the reference where from the maritime zones are measured, are the baselines demarcating land territory and internal waters from the sea as they are portrayed on large-scale charts officially recognized by the coastal states involved. This requirement in itself poses a number of questions as to how a base-line is defined with respect to the selected vertical datum, the configuration of the coast line, and the position of the coast line itself and whether there are special types of baselines like bay-closing lines and the way they are delineated.

Upon completion of the definition of the reference lines, the delineation of the maritime zones and boundaries should be implemented. The variety of the zones stipulated by UNCLOS and their respective distances from the reference lines but mainly the multitude of geographic configurations of the adjacent states involved, raise a number of problems that must be addressed. These problems relate to the horizontal reference surface that must be used for the delineation, the methodology that should be followed and its accuracy requirements and finally the carto-graphic characteristics of the chart (e.g. projection, scale) where the resulting lines/zones/boundaries will be portrayed on.

Until recently the delimitation was performed manually or semi-manually on paper charts. Given that digital technology and its geographic applications enable those involved to utilize their functionality, it is obvious that the solutions to the above mentioned problems should be carried out in a digital environment. This in general speeds up the process, gives accurate results, and leads to the building of a worldwide coverage database of maritime zones and boundaries that is an additional requirement at the level of the United Nations. The evaluation of the existing commercial software solutions shows that the delineation of bay-closing lines and the delimitation of maritime zones and boundaries constitute complicated and time consuming tasks that require continuous user intervention in a number of stages.

\subsection{Baselines}

It becomes evident that baseline is one of the fundamental concepts in LOSC as it divides the land and the in-land waters from the sea and serves as the reference where from the maritime zones are measured. Baselines normally coincide with the low-water line (normal baseline) as marked on large-scale charts officially recognized by the coastal State (rule of tidemark). The low-water mark prevailed over the high-water mark as it gives the coastal state the right to measure the maritime zones from the outermost land above water at low tide (Shalowitz 1962). Alternatively, in localities where the coastline is deeply indented or cut into, or if there is a fringe of islands along the coast in its immediate vicinity, straight baselines may also be used.

The concept of straight baselines was introduced to the international law with the Anglo-Norwegian case in which Norway drew straight lines along the Norwegian coast (Fisheries Case 1951). Much of the Norwegian coast is dominated by the so called skjaergaard (meaning rock rampart), fjords formations fringed by numerous islands, rocks and reefs. Norway had been using straight lines since the mid-19th century, a practice contended by the United Kingdom. The dispute was eventually taken to the International Court of Justice (ICJ) in 1949 and ultimately ICJ, in its 1951 judgment, upheld Norway's practice and found the system of straight baselines in conformity to the international law. From a technical perspective straight baselines prevent the construction of highly irregular outer limits impractical for the coastal state(s) and every other party involved, but they are permissible only where the local geography justifies such departure from the normal baseline. As they are codified in the Convention, straight base-lines may not be drawn from low tide elevations unless a lighthouse or similar installation, permanently above sea level, is built. They also cannot be drawn "in such a manner that they cut off the territorial sea of another State from the high seas or an exclusive economic zone".

\subsection{Juridical bays}

According to the 1982 convention, a bay is "a wellmarked indentation whose penetration is in such proportion to the width of its mouth that it contains landlocked waters and constitutes more than a mere curvature of the coast". With the exception of historic bays, for which there are no such requirements, an indentation qualifies as a juridical bay when two objective criteria are met. Firstly, the length of the bay closing line does not exceed $24 \mathrm{NM}$ and secondly, the enclosed area is at least as large as, or larger than, that of the semi-circle whose diameter equals to the length of the closing line. The waters on the landward side of the closing line constitute inland waters and the closing line itself becomes a part of the baseline from which the maritime zones are measured. On the contrary, if either of the criteria is not satisfied the bay is not considered legal.

\subsection{Unilateral and bilateral limits}

The delimitation of maritime outer limits begins with the selection of the proper nautical charts officially recognized by the coastal state(s), which depict the coastline(s) at the largest possible scale. Charts are used either for the graphical construction of maritime zones directly on them or as a source of basepoints' (any point 
on the territorial sea baseline) coordinates for use with GIS software. One can distinguish between two broad categories; unilateral and bilateral limits. The former is the case when, in the absence of overlapping claims between the maritime zones of neighboring states, the coastal state has the right to claim its outer limits to the maximum extent. On the contrary, bilateral are the limits when the maritime zones of two neighboring coastal states (either adjacent or opposite), at their maximum extent, overlap. Unilateral or bilateral, outer limits can be constructed graphically or automatically utilizing one of the existing GIS software.

\section{Implementation requirements}

Bay-closing lines: Formerly, validating both length and semi-circle criteria for the identification of indentations entitled to be closed as juridical bays was carried out with the use of traditional graphical methods on large-scale paper charts. This approach is complicated and timeconsuming, furthermore introducing errors on both length and area measurements. The development of GIS and semi-automatic applications for the validation of the length and semi-circle criteria, made the process more efficient. In these applications, the user is called upon to select an indentation and draw the candidate bay-closing line with the software proceeding with the validation of the two criteria and returning a response as to whether an indentation is a juridical bay. The inherent weakness of this process is that the detection of candidate juridical bays depends on the user's judgment and, as such, indentations meeting both criteria may remain undetected. Furthermore, contrary to the case of bay I in Fig. 3 which is straightforward and the semi-automatic routines encounter no problems to validate both criteria; significant difficulties appear in situations where the candidate closing line crosses islands located in the mouth of the bay (bay II, Fig. 3).

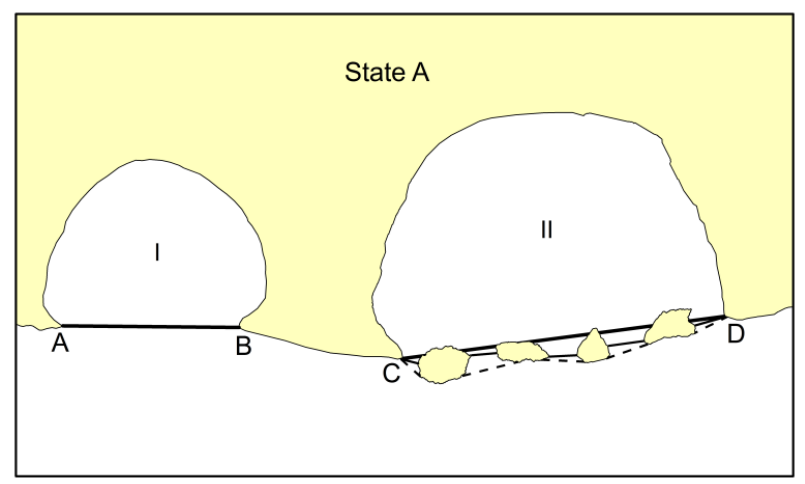

Fig. 3. Candidate bay-closing lines in the case of islands located in the mouth of the bay. (Source: Kastrisios and Tsoulos, 2016a)

Maritime zones and boundaries: The dominant method for the unilateral delineation of maritime zones to their maximum allowable breadth has been that of the conventional line constructed as the combination of the envelope of arcs for the normal coastline and the replica line (also known as tracé parallèle) for straight baselines. To implement the envelope of arcs, from every point on the normal baseline an arc is drawn at a distance equal to the breadth of the maritime zone (Boggs 1930) and the, so called, envelope line is the locus of the intersections of the farthest arcs. This is compliant with the provisions of the UNCLOS for a line "every point of which is at a distance from the nearest point of the baseline equal to the breadth of the territorial sea", which is inferred to be applicable as well to the other maritime zones. On the other hand, the replica line is created with the transfer of the straight line segments seawards at a distance equal to the zone's breadth. The outer limit of the maritime zone is formed by the combination of the two lines (Fig.4).

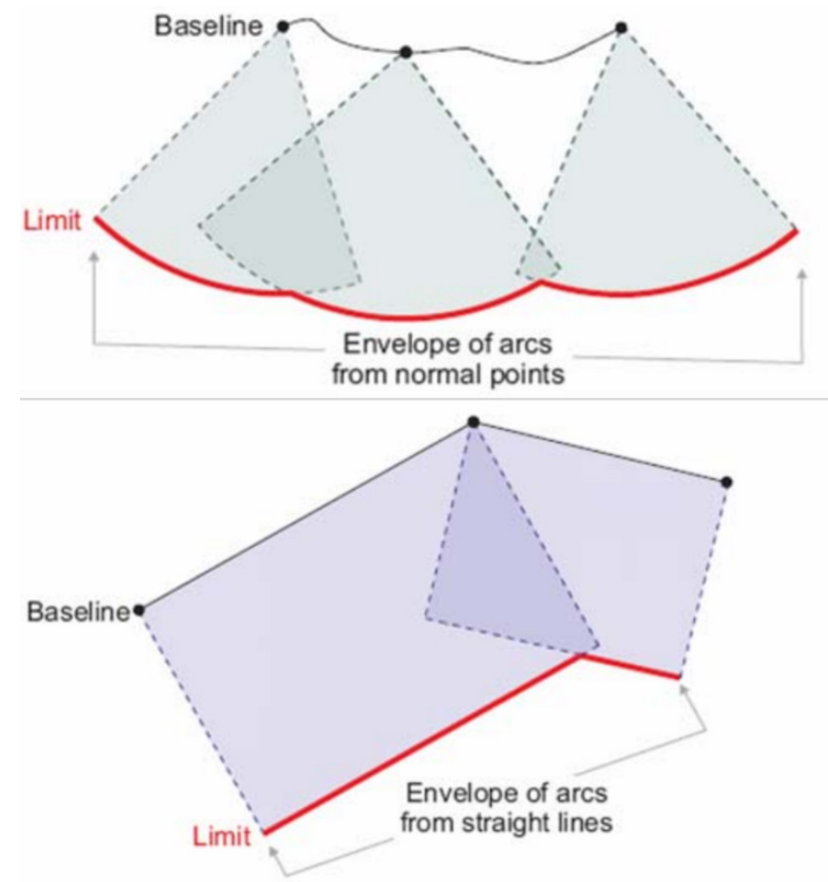

Fig. 4. The outer limit of a maritime zone is a combination of the envelope of arcs and the replica lines. (Source: Levesque et al. 2008)

With respect to the bilateral delineation of maritime limits, that is when the respective maritime zones of two coastal states overlap, the cartographer must define the median line "every point of which is equidistant from the nearest points on the baselines". The cartographer needs to delimit the median lines between normal baselines for all possible combinations of the respective states, then for the normal and straight lines and finally between straight lines. The process is performed for parts of the region and is repeated for the full extent of the baselines. Then, the results are manually combined to compose the median lines between the states involved. Following the formation of the median lines and for the bilateral delimitation of maritime zones, the cartographer constructs the zones at their maximum breadth and subsequently clips them so that they do not extend beyond the median line.

It becomes evident that the available solutions although they facilitate the tasks involved in the various stages of delineation of maritime boundaries, they address the subject in a fragmented, semi-automated, time-consuming and error prone way. Therefore, the development of a 
cohesive methodology that addresses the above mentioned constraints was considered necessary and integrated solutions to the problems were developed in the framework of a research work (Kastrisios and Tsoulos 2016a; Kastrisios and Tsoulos 2016b).

\section{Methodological approach}

Bay-closing lines: According to the proposed methodology for the detection of all juridical bays (Kastrisios and Tsoulos 2016a) along a coastline the requirements that a fully automated process must address are formulated as follows:

1) It must examine the coastline points in their entirety, meaning to consider every point on the coastline as a possible entrance point and examine it in combination with every other point aiming at locating all possible pairs that, after joining, lead to acceptable results.

2)Carry out a process for the location of bays throughout the length of a coastal state's coastline "in such a manner as to enclose the maximum area of water that is possible with a line of that length".

3 ) Locate the entrance points at the mouth of the candidate bay and validate the length criterion for the bay-closing line joining these points.

4)Calculate the area of the polygon formed by the coastline and the bay-closing line and validate the semi-circle criterion. In calculating the area of the bay it must calculate the area of the islands located within the bay along with the water area, because "islands within an indentation shall be included as if they were part of the water area of the indentation".

5) Where the distance between the low-water marks of the entrance points of a bay exceeds $24 \mathrm{NM}$, it must detect two other points within the indentation, should they exist, concurrently meeting the length and semi-circle criteria.

6) Likewise, in indentations where the length criterion is met for the entrance points, but not that of semicircle, it must locate two such other points in the indentation that concurrently meet both criteria.

7)Disregard and not examine an indentation generated by the coastlines of two States, although this may meet the length and semi-circle criteria, as, a bay exists only if formed by the coastlines that belong to a single state.

8)Detect all possible choices of bays created by the local geography, which: (a) may overlap, but (b) none of them may be fully included in the others. In these cases, although, the presumable choice is the bay enclosing the largest water surface, the final choice must be in the end user's discretion.

9) When islands are located in the mouth of a bay, it must delimit the bays created: (a) by the straight line joining the two points on either side of the indentation, whose length must be reduced by the part crossing the islands, (b) by the segmented line joining the mouths between the islands whose length will be the sum of the individual segments.
10) If an indentation exists for which there are two other points that are not obvious headlands but after joining meet both criteria, then it must detect the points as well as the bay formed.

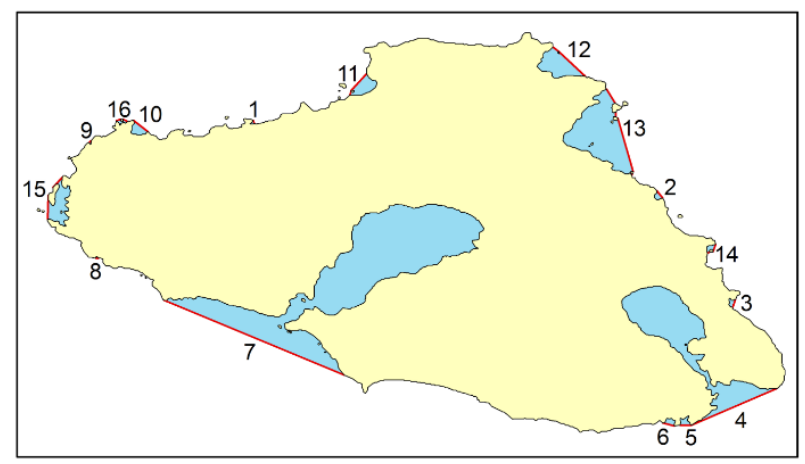

Fig. 5. Juridical bays and their respective bay-closing lines for Lesbos Island, Greece. (Source: Kastrisios and Tsoulos 2016a)

The above mentioned requirements have been expressed in an algorithmic way and subsequently encoded in Python for use in the ArcGIS environment. In the case of Fig. 5, the application successfully delineated all juridical bays of Lesbos Island, including those with islands located in the mouth of the bay $(11,12,13,14$, and 15 in Fig.5).

Maritime zones and boundaries: The requirements that a fully automated process must address for the delineation of maritime zones and boundaries are formulated as follows.

1)Delineate all maritime zones unilaterally at their maximum breadth, with their inner limits being in accordance with those included in section 2.1.

2)Delimit the median line between opposite baselines.

3)Delimit the median line between adjacent baselines.

4)Delimit the maritime zones bilaterally up to the median line in areas where the maritime zones of two coastal states overlap.

5)Determine the critical points on the baselines that contribute to the delineation of each zone and the turning points of the median line (namely the points where the limit changes direction) and the zones' outer limits.

6)Delineate the median lines and maritime zones and limits as described in requirements (1) - (5) when mixed baselines are used.

7)Process the above requirements (1) - (6) without human intervention for the full extent of the baselines and for all coastal states in the region concurrently.

For the delineation of the median line, the algorithm and the application developed utilize the Voronoi tessellation.Voronoi Tessellation (also known as Thiessen Polygons), a computational geometry method introduced by the Russian mathematician Georgy Voronoi (1907), has found application in a variety of disciplines, including geogra-phy and geosciences (Aurenhammer 1991; Okabe et al. 2000). Given a finite set of points, Voronoi assigns 
to each point a region of influence in such a way that the regions decompose the $\mathrm{R} 2$ space. To describe this, let $\mathrm{S} \subseteq$ $\mathrm{R} 2$ be a set of points, the Voronoi tessellation associates to each point $p \in S$ a Voronoi cell $\mathrm{Vp}$ such that (Edelsbrunner 2001):

$$
V_{p}=\left\{x \in R^{2} \mid\|x-p\| \leq\|x-q\|, \forall q \in S\right\}
$$

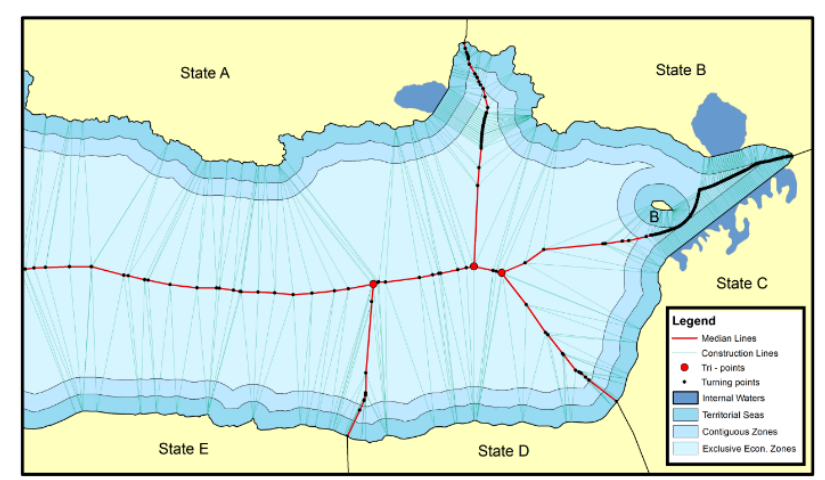

Fig. 6. The median lines and the maritime zones for all coastal states in the study area as delineated by the application. (Source: Kastrisios and Tsoulos 2016b)

Voronoi can be implemented on planar, spherical (e.g. Caroli et al. 2009) or ellipsoidal ( $\mathrm{Hu}$ et al. 2014) reference surfaces. In maritime delimitation the surface to be used depends on the distances between the states involved. In two dimensions the Voronoi region is a convex polygon and the edges are straight lines. In three dimensions it is a convex polyhedron and the edges are either arcs of circles or geodesics depending on the reference surface used. The advantage of Voronoi tessellation that makes it useful in maritime delimitation, is the partition of space into regions where every point's distance to its generator is less or equal to its distance to any other generator, and hence the locus of points for which $\|\mathrm{x}-\mathrm{p}\|=\|\mathrm{x}-\mathrm{q}\|$ is represented by the Voronoi edges. This attribute has already been suggested for boundary delimitation by Gold (2000), Cosquer \& Hangouët (2003), Lygeros (2012) and $\mathrm{Hu}$ et al. (2014) without this being the sole method that may be used towards an automatic solution, e.g. Carrera (1987), Sjöberg (2002), Ferrero et al. (2009). On the other hand Voronoi regions are stored in a concrete topological structure that maintains spatial relationships, which can be utilized for the solution of a number of problems relevant to the delimitation process. The role of generators is undertaken by the vertices comprising the baselines (basepoints), while the resulting Voronoi edges shared between Voronoi cells of the coastal states in question comprise parts of the median lines. Fig. 6 illustrates the results of the delimitation for a study case of five coastal states in a fictitious area, including their maritime zones delineated unilaterally and bilaterally up to the median lines.

\section{Conclusions}

This paper briefly discussed fundamental concepts of the UNCLOS, including maritime zones and baselines, as well as technical issues associated with their delineation. It explored two of the problems associated with the automation of the delimitation process, i.e. the determination and delineation of juridical bays and the delimitation of median lines and maritime zones. It presented the requirements of the desired integrated applications, methodological approaches for meeting those requirements and their implementation in python programming language for use in a GIS environment. Using the results of the two case studies, it is demonstrated that with the applications developed the cartographers and other professionals working in the field may accurately determine the indentations entitled to be closed as juridical bays and delineate the median lines among all coastal states in the region without user's intervention. Both applications examine baselines in their entirety making the calculations on the ellipsoidal earth. The latter application constructs the median lines and maritime zones for both adjacent and opposite base-lines, for mixed baselines (any combination of normal and straight baselines), and for multiple states concurrently. In addition, it determines the turning points of the limiting lines, the contributing points on the baselines and the respective construction lines with their geocoordinates stored in a list for subsequent inclusion in the relevant legal documents of the agreement.

\section{References}

A Manual On Technical Aspects Of The United Nations Convention On The Law Of The Sea - 1982 (TALOS), Special Publica-tion No. 51, 5th Edition, Monaco: IHO.

Aurenhammer, F. (1991). Voronoi diagrams: a survey of a fundamental geometric data structure. ACM Computing Surveys 23, 345-405.

Boggs, S.W. (1930). Delimitation of the territorial sea: the method of delimitation proposed by the delegation of the United States at the Hague Conference for the Codification of International Law. American Journal of International Law 24 (3), 541-545.

Caroli, M., et al. (2009). Robust and efficient Delaunay triangulations of points on or close to a sphere. Research Report RR-7004.

Carrera, G. (1987). A method for the delimitation of an equidistant boundary between coastal states on the surface of a geodetic ellip-soid. International Hydrographic Review, LXIV(1): 147-159.

Cosquer, G., Hangouët, J.F. (2003). Delimitation of Land and Sea Boundaries: Geodetic and Geometric Bases. FIG Working Week 2003, Paris, France, April 13-17, 2003.

Edelsbrunner, H. (2001). Geometry and Topology for Mesh Generation. Cambridge University Press, Cambridge, England.

Ferrero, S.M, et al. (2009). An algorithm for the unambiguous determination of the equidistant boundary line between two (or more) coastlines, Appl. Geomat.1:49-58, DOI 10.1007/s12518-009-0007-z.

Fisheries Case (UK v. Norway), Judgment, 18 December 1951, ICJ Reports 116, p.116. 
Gold, C.M. (2000). An algorithmic approach to marine GIS. In Wright, D., \& Bartlett, D. (Eds.), Marine and Coastal Geographical Information Systems, chapter 4, p.37-52.

Hodgson, R.D., \& Alexander, L.M. (1972). Towards an objective analysis of special circumstances: bays, rivers, coastal and oceanic archipelagos and atolls, Law of the Sea Institute, Occasional paper, no. 13. Kingston, R.I.: Law of the Sea Institute.

$\mathrm{Hu}, \mathrm{H}$., et al. (2014). Voronoi diagram generation on the ellipsoidal earth. Computers \& Geosciences 73, 81-87.

Kastrisios, C. (2014). Methods of Maritime Outer Limits Delimitation, Nafsivios Chora, Vol.5/2014, Piraeus, p. E3-E22, http://nausivios.snd.edu.gr/docs/2014E1.pdf . Accessed 21 February 2017.

Kastrisios, C., Tsoulos, L. (2016a). An integrated GIS methodology for the determination and delineation of juridical bays, Ocean \& Coastal Management, Vol. 122, March 2016, Pages 30-36. doi:10.1016/j.ocecoaman.2016.01.005.

Kastrisios, C., Tsoulos, L. (2016b). A cohesive methodology for the delimitation of maritime zones and boundaries. Ocean \& Coastal Management, 130(3), 188-195. doi:10.1016/j.ocecoaman.2016.06.015

Levesque, S., Cockburn, S., McLeay, C. (2008). Modern developments in geospatial management and their use in marine cadastre. Proceedings of the Advisory Board on the Law of the Sea to the International Hydrographic Organization (ABLOS) Conference "Difficulties in Implementing the Provisions of UNCLOS." Presented at the International Hydrographic Bureau, Monaco, October 2008.

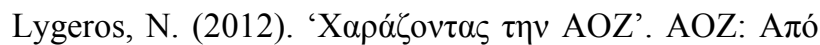

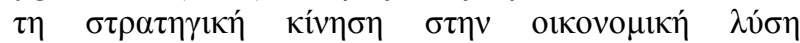
[Delimiting EEZ: From the stra-tegic move to the

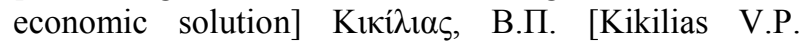

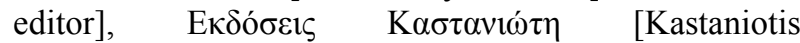
publications], A $\theta \dot{v} v \alpha$ - Athens, 2012 (in Greek).

Okabe, A., et al. (2000). Spatial Tessellations: Concepts and Applications of Voronoi Diagrams (2nd ed.). John Wiley \& Sons, Inc., Hoboken, NJ, USA.

Shalowitz, A.L. (1962). Shore and Sea Boundaries, Vol. 1, Washington: U.S. Dept. of Commerce, Publication 10-1, U.S. Govt. Print-ing Office.

Sjoberg, L.E. (2002). The Three-point Problem of The Median Line Turning Point: on the Solutions for the Sphere and Ellipsoid. The International Hydrographic Review, 3, 81-87.

UN (United Nations), Convention on the Law of the Sea (UNCLOS), Montego Bay, 10 December 1982, 1833 United Nations Treaty Series 3, 21 I.L.M., entered into force 16 November 1994.

Voronoi, G. (1907). Nouvelles applications des paramètres continus à la théorie des formes quadratiques. Premier Mémoire: Sur quelques propriétées des formes quadritiques positives parfaites. J. Reine Angew. Math. 133:97-178. 